\title{
Effects of Curing Conditions on Properties of Fly Ash-based Geopolymer Concrete
}

\author{
Xue-Hua YE ${ }^{1, a,{ }^{*}}$, Jin-Yu XU1,2,b \\ ${ }^{1}$ College of Mechanics and Civil Architecture, Northwest Polytechnic University, Xi'an 710072, China \\ ${ }^{2}$ Department of Airfield and Building Engineering, Air Force Engineering University Engineering \\ College, Xi'an 710038, China \\ ayexuehua_afeu@163.com, bperwit@163.com \\ ${ }^{*}$ Corresponding author
}

Keywords: Geopolymer Concrete, Curing Condition, Compressive Strength, Flexural Strength, Permeability Coefficient.

\begin{abstract}
The fly ash-based geopolymer concrete (FAGC) were prepared by using fly ash as the main binder. The influences of curing conditions on mechanical properties and permeability were investigated by compressive test, flexural test and permeability test. The results indicate that elevated temperature curing accelerates the early reaction of FAGC, which is conducive to its early strength. Proper steam curing is beneficial to the early flexural strength of FAGC. While the flexural strength decreases under a long-time and high-temperature steam curing. Elevated temperature curing is bad for the strength development of FAGC. The strength increases slowly under a long-time and high-temperature steam curing. This is related with the decreased compactness and porous structure degradation caused by elevated temperature curing.
\end{abstract}

\section{Introduction}

Geopolymer concrete (GC) is a new environmentally friendly composite. The binder materials used for GC are mostly the industrial wastes or by-products containing high contents of silica and alumina and the manufacturing of these pozzolanic materials consumes less energy and emits less $\mathrm{CO}_{2}[1-3]$. Compared with the production of Portland cement, Hence, in the context of sustainability and environmental issues, concretes produced using geopolymers as binder are attracting more and more interests.

The binder materials of GC such as fly ash, blast furnace slag, metakaolin, are containing high contents of silica and alumina, which can be applied as pozzolanic components for geopolymerization in alkaline environments[4]. A wealth of researches [5-7] conducted in the past several decades study the static mechanical properties, dynamic mechanical properties of $\mathrm{GC}$ but have little research on the effect of different curing condition to GC[8,9]. Since different curing condition lead to different properties of $\mathrm{GC}$, such as the rate of hardening, the interface product, the pore structure, therefore, different behaviors of GC caused by different curing condition need to be investigated.

Thus in this paper, FAGC is prepared by using fly ash as main binding material and sodium silicate, sodium hydroxide as alkali-activator. The macro-mechanical properties and the penetrating quality of FAGC was experimentally investigated through compressing test, bending test and impermeability test. Different properties caused by different curing condition were discussed.

\section{Experimental Methods}

\section{Materials and Specimen Preparation}

Materials involved in this research included low calcium fly ash, metakaolin with 1250 fineness, sodium silicate(modulus $3.2,8.2 \%$ of $\mathrm{Na}_{2} \mathrm{O}, 26.2 \%$ of $\mathrm{SiO}_{2}$ ), sodium hydroxide, water, respectively. Crushed limestone with nominal maximum size of $20 \mathrm{~mm}$ and natural river sand were used as coarse 
aggregate and fine aggregate, respectively. Mix proportions of FAGC are listed in Table 1. Alkali-activator (modulus 1.4, mass fraction 30\%) is made by mixing of sodium hydroxide, sodium silicate and water. The mass of metakaolin is $15 \%$ the sum of metakaolin and fly-ash and the ratio of alkali-activator and solid state binding material is 0.5 .

Tab.1 Mix proportions of FAGC $\mathrm{kg} / \mathrm{m}^{3}$

\begin{tabular}{ccccccc}
\hline Fly ash & $\begin{array}{c}\text { Metakaoli } \\
\mathrm{n}\end{array}$ & Rubble & Sand & Sodium silicate & $\begin{array}{c}\text { Sodium } \\
\text { hydroxide }\end{array}$ & Water \\
\hline 383 & 68 & 1032 & 688 & 141 & 28 & 58 \\
\hline
\end{tabular}

Alkali-activator is prepared one day before the test and store sealed. Coarse aggregate and fine aggregate were initially dry mixed for $120 \mathrm{~s}$, later, solid state binding material was added and mixed for another $90 \mathrm{~s}$. Finally, alkali-activator were put into mixer and mixed for $120 \mathrm{~s}$. After mixing, mixtures were cast into moulds and compacted with vibrating table. Specimens were demoulded and removed into standard curing room (with a temperature of $20 \pm 2{ }^{\circ} \mathrm{C}$ and a relative humidity of $95 \%$ ) for $24 \mathrm{~h}$ curing. After $24 \mathrm{~h}$ curing, elevated temperature curing of $50{ }^{\circ} \mathrm{C}$ and $80{ }^{\circ} \mathrm{C}$ was putting into effect with $4 \mathrm{~h}, 8 \mathrm{~h}$ and $12 \mathrm{~h}$, respectively. Then specimen was putting into standard curing room for $7 \mathrm{~d}, 28 \mathrm{~d}$ and $90 \mathrm{~d}$, respectively. Finally, the compressing test, bending test and impermeability test were putting into effect.

\section{Experimental Procedure}

Compressing test and bending test are conducted referring to China standard (GB/T 50081-2002), $150 \mathrm{~mm} \times 150 \mathrm{~mm} \times 150 \mathrm{~mm}$ specimen is prepared for compressing test, $600 \mathrm{~mm} \times 150 \mathrm{~mm} \times 150 \mathrm{~mm}$ specimen is prepared for bending test, respectively. Impermeability test is conducted referring to China standard (GBT 50082-2009) and (SL 352-2006), the round estrade specimen with top diameter $175 \mathrm{~mm}$, bottom diameter $185 \mathrm{~mm}$, height $150 \mathrm{~mm}$, is prepared and the water gage is $1.2 \pm 0.5 \mathrm{MPa}$, action time is $24 \mathrm{~h}$, respectively. Since the hydration reaction of $7 \mathrm{~d}$ specimen is fast that there will be huge error in test.The curing period of test specimen is $28 \mathrm{~d}$ and $90 \mathrm{~d}$.

\section{Results and Discussion}

\section{Compressive Strength}

The compressive strength of different curing temperature and different curing period is discussed in this part. As presented in Fig.1, the strength of FAGC at a fixed temperature increases continuously with increasing curing period and the increasing curing temperature. At curing period of $28 \mathrm{~d}$, the compressive strength of FAGC increases at first and decreases at follow with increasing of curing temperature. At curing period of $90 \mathrm{~d}$, the compressive strength of FAGC decreases with increasing curing temperature and curing period.

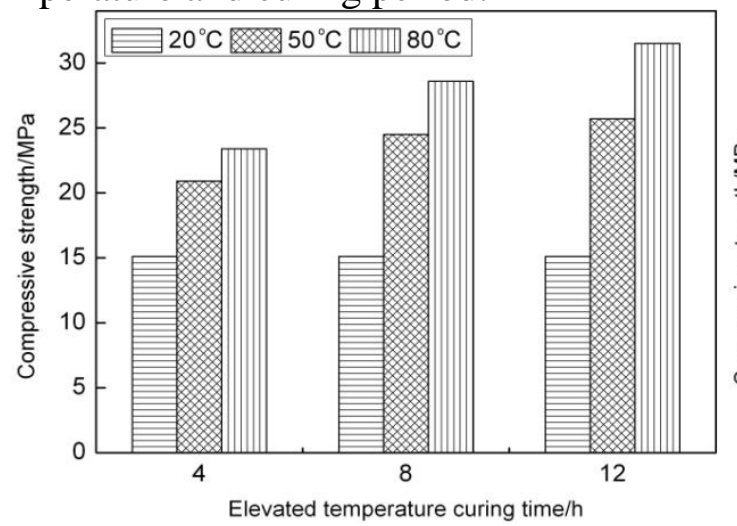

(a) $7 \mathrm{~d}$

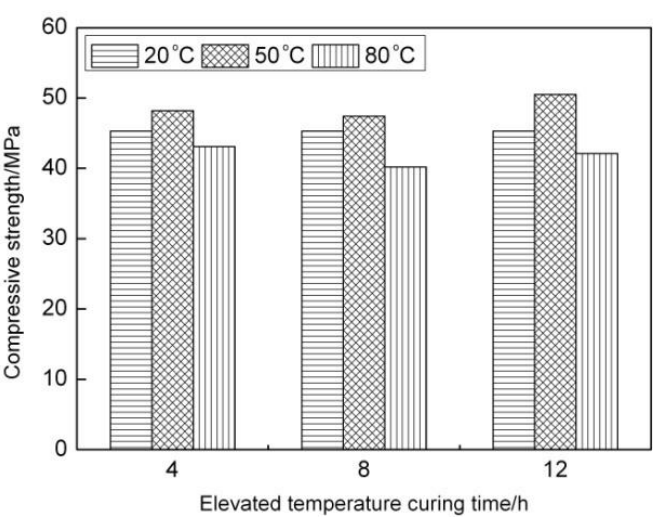

(b) $28 \mathrm{~d}$ 


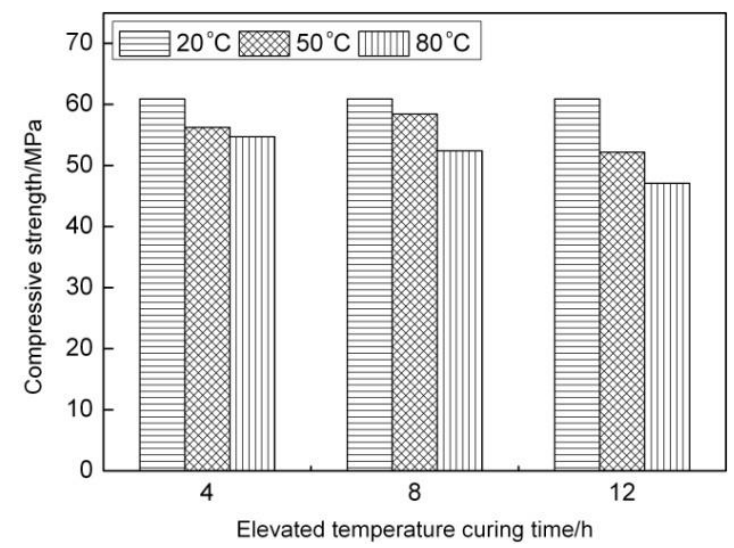

(c) $90 \mathrm{~d}$

Fig. 1 Compressive strength of FAGC under various curing conditions

The analysis above shows that elevated curing temperature is beneficial to the early compressive strength and decreasing the later compressive strength with increasing cure period. The effect of strength decreasing becomes sharper with increasing curing temperature and period. The research of Pavel Rovnaník[10] implies the main influence factor to compressive strength is the quantity of polymerizate. The research of Glukhovsky[9] claims the velocity of setting and hardening is controlled by the velocity of deconstruction and reconfiguration, the velocity of reconfiguration increases with activity of ion increasing and temperature increasing.

Therefore, the early strength can be improved by curing temperature because of the velocity of deconstruction and reconfiguration. The fast reaction of FAGC extends with steam-curing period increasing, the early compressive strength is increasing at the same time. After steam-curing, the velocity of steam-cured specimen and unsteamed specimen are becoming the same by the consuming of the effective constituent in aqueous alkali. The main influence factor of compressive strength is the mass of polymerizate after long period curing. Since more quantity of heat released at elevated temperature, the porosity increases and the density decreases of the specimen. At the same time, the velocity of unsteamed specimen becomes more uniform and higher later strength acquired. The research of Fernández[11] implies that the order of dissolve is large vitreum, small vitreum and new gel production will stay at the surface of the vitreum, since the vitreum surrounded by small vitreun, the deconstruction will cease. With steam-cured environment, lots of gel are formed during short time and will not disperse soon, thus the deconstruction is stopped because of vitreum surrounded. Therefore, the later strength of FAGC decreases even then the early strength is increasing at elevated curing temperature.

\section{Flexural Strength}

The flexural strength of different curing temperature and different curing period is discussed in this part. As presented in Fig.2, the flexural strength of FAGC increases at first and decreases at follow with increasing of curing temperature. The strength of FAGC at $50{ }^{\circ} \mathrm{C}$ temperature increases continuously with increasing curing period but decreases at $80^{\circ} \mathrm{C}$. At curing period of $90 \mathrm{~d}$, the flexural strength of FAGC decreases with increasing curing temperature and curing period.

The analysis above shows that influence of elevated temperature for flexural strength is different compared to compressive strength. Proper steam-curing temperature and steam-curing period are beneficial to the early flexural strength $(7 \mathrm{~d}, 28 \mathrm{~d})$, and the further improvement of steam-curing temperature and steam-curing period will do harmful to the flexural strength of FAGC. At the same time, unsteamed specimen has a better flexural strength with increasing curing period. The reason is that early steam-curing at elevated temperature do helpful by promoting polyreaction but do harmful by decrease the density of specimen at the same time. Different reaction between compressive strength and flexural strength come to the fact that the property of flexural strength is more sensitive to density. The main reason is that quick losing of water in FAGC with steam-curing at elevated 
temperature and the losing water will not be replenished by steam-curing[12]. Thus more hole are formed and lead to more micro-cracks. These micro-cracks have little influence to compressive strength but do harmful to flexural strength because of stress concentration. So the flexural strength decreases when there are further improvement of steam-curing temperature and steam-curing period. In general, proper steam-curing temperature and steam-curing period are beneficial to the early flexural strength but do harmful to the later flexural strength.

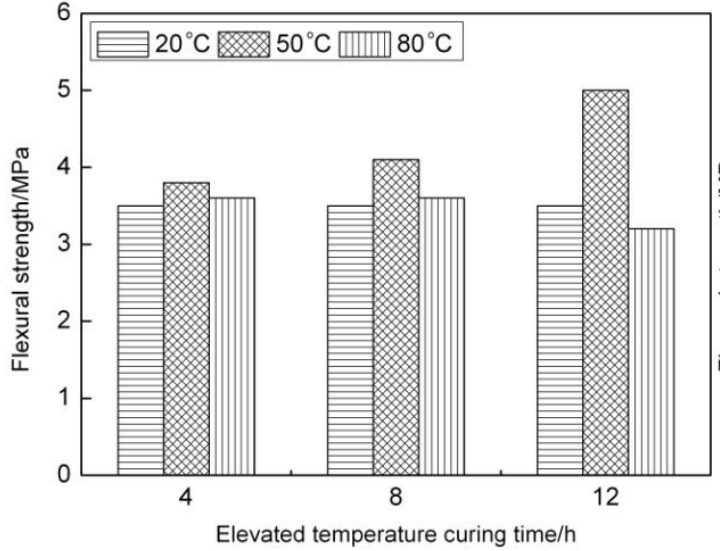

(a) $7 \mathrm{~d}$

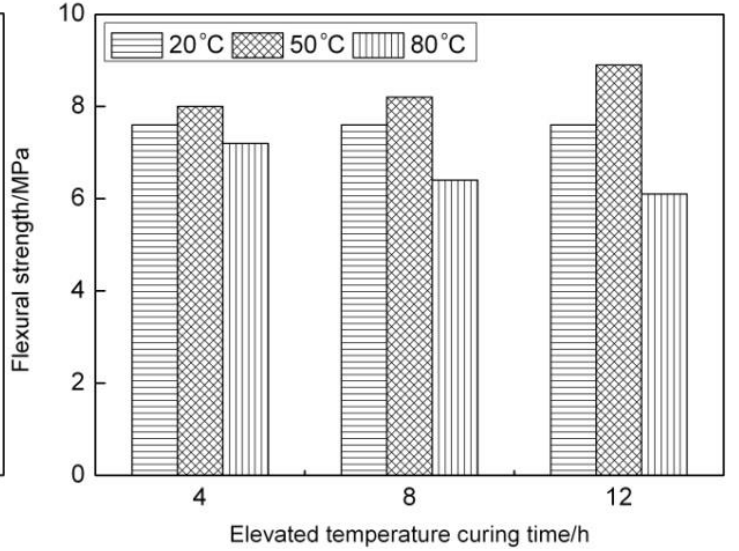

(b) $28 \mathrm{~d}$

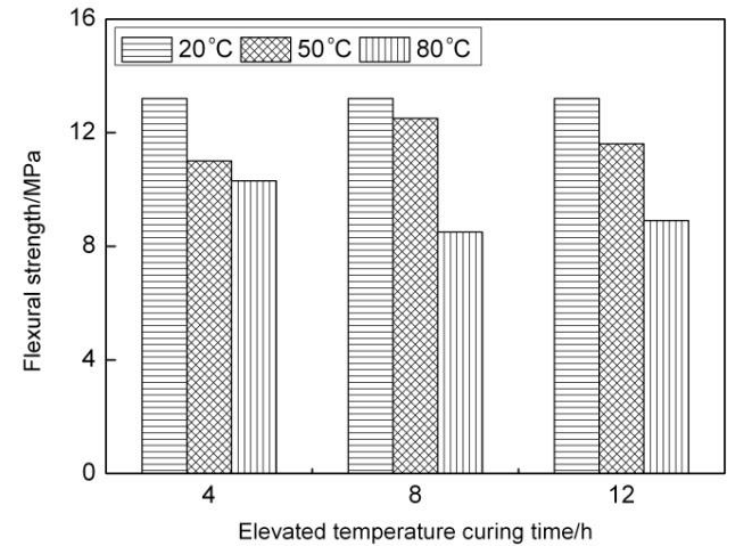

(c) $90 \mathrm{~d}$

Fig. 2 Flexural strength of FAGC under various curing conditions

\section{Impermeability}

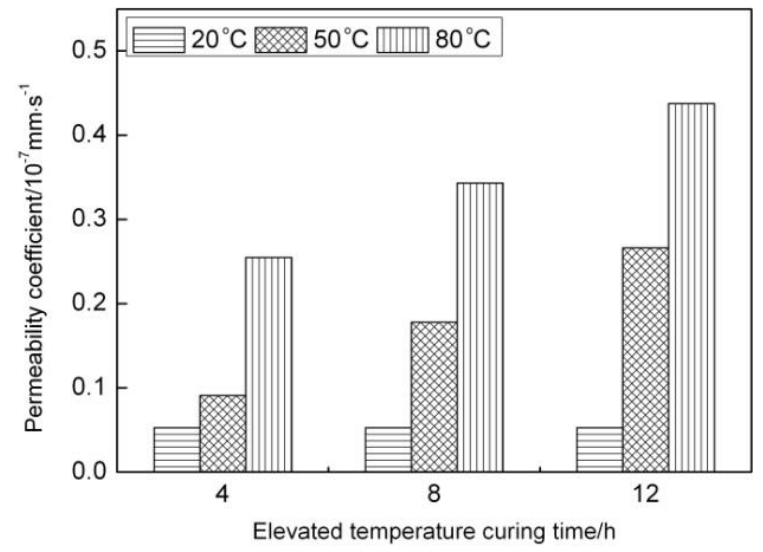

(a) $28 \mathrm{~d}$

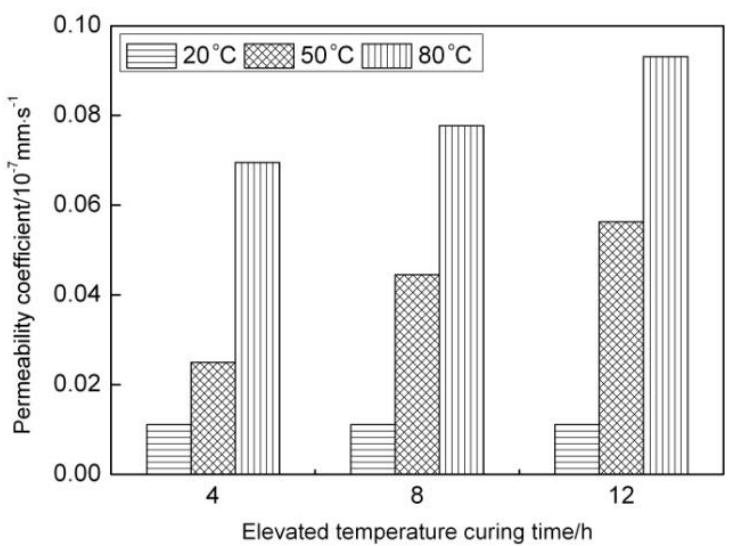

(b) $90 \mathrm{~d}$

Fig. 3 Permeability coefficient of FAGC under various curing conditions

The analysis above shows there is intimate relationship between strength and the density of FAGC, the impermeability test at different curing environment is conducted to study further about the relationship. Impermeability is an important property of concrete and it has intimate relation with 
density and the hole structure[13]. The permeability coefficient of FAGC in different curing environment is discussed in this part. As presented in Fig.3, The permeability coefficient increases with the improvement of steam-curing temperature and steam-curing period. It implies that the density of FAGC decreases and it fits the result of compressive strength well. Since the formed polymerizate fill the hole, the permeability coefficient decreases with increasing curing period.

\section{Conclusions}

(1) Steam-curing at elevated temperature accelerate the early polyreaction and is beneficial to the early compressive strength of FAGC. The improvement of steam-curing temperature and period can improve the early compressive of FAGC at appropriate level. The further improvement of steam-curing temperature and period will do harm to the early flexural strength of FAGC.

(2) Higher the steam-curing, slower the increasing velocity of later strength of FAGC because of the steam-curing at elevated temperature decrease the density of FAGC and have degradation of hole structure. The flexural strength is more sensitive to the density of FAGC.

(3) The density of FAGC increases with increasing curing period but the degradation of elevated temperature curing has no help to supply the gap.

\section{Acknowledgement}

We gratefully acknowledge the financial support from Projects of National Natural Science Foundation of China (51208507, 51378497), Industrial Public Relation Project for science and technology development in Shaanxi province China (2014K10-15), Projects of youth technology new star of Shaanxi province China (2013KJXX-81).

\section{References}

[1]Bakharev T. Geopolymeric materials prepared using Class F fly ash and elevated temperature curing, Cement and Concrete Research. 35(2005)1224-1232.

[2]YIN Ming, BAI Hong-tao, ZHOU Lv. Strength characteristics of fly ash based geopolymer concrete, Bulletin of the Chinese Ceramic Society. 33 (2014)2723-2727. (in Chinese)

[3]Lee N K, Lee H K. Setting and mechanical properties of alkali-activated fly ash/slag concrete manufactured at room temperature, Construction and Building Materials. 47(2013) 1201-1209.

[4]Puligilla S, Mondal P. Role of slag in microstructural development and hardening of fly ash-slag geopolymer, Cement and Concrete Research. 43 (2013) 70-80.

[5]DING Qing-jun, WU Jing, LV Lin-nv, et al. Study on new type geopolymer-based lightweight high-temperature concrete, Concrete. 3 (2007) 1-3.(in Chinese)

[6]LIU Yong-dao, LU Du-you, ZHENG Yan-zeng. Effect of curing conditions on the deformation behaviour of fly-ash based geopolymer, Bulletin of the Chinese Ceramic Society. 30 (2011):1228-1232. (in Chinese)

[7]Partha S D, Pradip N, Prabir K S. Strength and permeation properties of slag blended fly ash based geopolymer concrete, Advanced Materials Research. 651(2013)168-173.

[8]XIE Zi-ling, LI Xian. Effect of curing temperature and curing time on compressive strength of fly ash geopolymer concrete, Concrete. 6 (2014):55-58. (in Chinese)

[9]Rovnaník P. Effect of curing temperature on the development of hard structure of metakaolin-based geopolymer, Construction and Building Materials. 24(2010)1176-1183.

[10]Glukhovsky V D. Soil silicates. Their Properties, Technology and Manufacturing and Fields of Application. Kiev: Civil Engineering Institute, 1965. 
[11]Fernández J A, Palomo A, Criado M. Microstruture development of alkali-activated fly ash cement: A descriptive model, Cement and Concrete Research. 35 (2005)1204-1209.

[12]Steenie E W. Drying shrinkage of heat-cured fly ash-based geopolymer concrete, Modern Applied Science. 3(2009)14-21.

[13]SUN Jia-ying. Study on influence of external load on fiber concrete impermeability, Journal of Building Materials. 15 (2012) 474-477.(in Chinese) 